\title{
E. A. Judge
}

\section{Jerusalem and Athens}

\section{Cultural Transformation in Late Antiquity Essays Selected and Ed. by Alanna Nobbs}

[Jerusalem und Athen. Kulturelle Transformation in der Spätantike.]

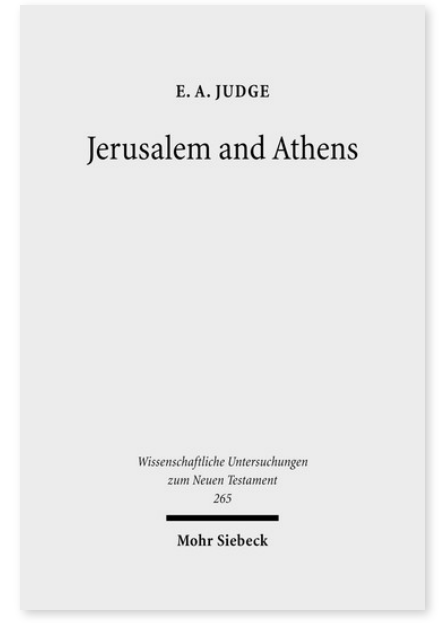

2010. XII, 352 Seiten. WUNT I 265

ISBN 978-3-16-151554-5

DOI 10.1628/978-3-16-151554-5

eBook PDF 129,00€

ISBN 978-3-16-150572-0

Leinen $129,00 €$
Veröffentlicht auf Englisch.

Die vorliegende Aufsatzsammlung behandelt die Wechselwirkung zwischen der klassischen und der biblischen Tradition, die kulturelle Transformation der Spätantike und das umstrittene Erbe Athens und Jerusalems im modernen Westen. Das Christentum entsteht vor allem aus einer Ideenbewegung, die zuerst einen Gegensatz zur kulturellen Praxis der zeitgenössischen Religion beinhaltete. Die neue Botschaft mit ihrer fordernden Moral legte die Grundsteine für unseren radikal anderen Sinn der 'Religion' als das Streben nach dem idealen Leben. Judges Methode beginnt mit Textdetails und besonderem Augenmerk auf die Dokumente aus der Zeit von Stein und Papyrus. Die Sammlung spiegelt einen holistischen Ansatz der Geschichte wider und macht die Bedeutung der Spätantike als eine wichtige Epoche in der kulturellen Entstehung der modernen Welt deutlich.

E. A. Judge Born 1928; Emeritus Professor of History at Macquarie University.

Alanna Nobbs Born 1944; Professor, Head of Department and Deputy Director at the Ancient Cultures Research Centre, Dept. of Ancient History at Macquarie University.

Jetzt bestellen:

https://mohrsiebeck.com/buch/jerusalem-and-athens-9783161515545?no_cache=1

order@mohrsiebeck.com

Telefon: +49 (0)7071-923-17

Telefax: $+49(0) 7071-51104$ 